\title{
15. CONSIDERAÇÕES POLÍTICAS SOBRE O ALIENISTA, \\ DE MACHADO DE ASSIS
}

\author{
José Antônio Gerzson Linck ${ }^{1}$ \\ Alexandre Costi Pandolfo
}

Resumo: este ensaio constitui-se uma leitura do estado de exceção em que vivemos a partir da obra O Alienista, de Machado de Assis. Faz uma análise da situação do Dr. Bacamarte e a da Casa Verde e das suas relações com a contemporaneidade.

Palavras-chave: Machado de Assis; Casa Verde; exceção; ensaio.

Abstract: From the work The Alienist by Machado de Assis, this essay is a reading of the state of exception in which we live. It studies the situation of Dr. Bacamarte and the situation of the Green House, and their relation with the contemporary.

Key-words: Machado de Assis; Green House; exception; essay.

Ó inevitável cortejo da razão, consciência doce da loucura, onde acharemos hoje método mais adequado para distinguir os loucos dos sãos? Sob controle, a loucura desenha ao contrário; mantém as aparências todas do império racional hegemônico; todas as insígnias e as silhuetas da paisagem social e familiar, retidas e seguras pelos

muros, pelo local marcado de um império que outrora edificara fortaleza visível e fora emblema da ordem - mas como orna-se agora o castelo da nossa consciência?

\section{Introdução}

Os sentidos todos são todos atrofiados quando o parâmetro é imposto externamente, quando a produção do saber sobre si é toda oferecida fora de si, de forma que o próprio relacionar-se consigo mesmo deva ser considerado fora de si. A produção do saber subjetivo sobre si mesmo é resistência às construções de saberpoder, visto que a legitimação de qualquer saber sobre o sujeito depende de uma

\footnotetext{
${ }^{1}$ Mestre e Doutorando em Ciências Criminais (PUCRS). Bolsista do projeto Descarcerização e Sistema Penal (Capes-CNJ Acadêmico).

${ }^{2}$ Mestre em Ciências Criminais (PUCRS). Doutorando em Teorias Críticas da Literatura (PUCRS), Bolsista CNPq. 
hierarquização tautológica cujo ponto de partida e de chegada é o mesmo: o sujeito não pode saber, se o sujeito souber sobre si então o saber sobre o sujeito teria de lidar com o saber do próprio sujeito. Tal hipótese seria incompatível com a legitimação que vincula norma e esquadro, bem como com a vinculação entre norma e média.

Ao mesmo tempo desempenhando o papel de assistência e de repressão, as instituições totais de internação como a Casa Verde jogam com cartas régias e animam as suas práticas sob movimentos nem sempre claros, sempre obnubilados, mas para cuja gestão é ainda possível encontrar as estruturas essenciais e concupiscentes entre burguesia, igreja e estado. Que tenhamos perdido ou ganhado algo em sua evidência, que isso ocorra abafado ou sufocado à percepção claramente articulada das suas consequências, isso designa uma situação de força, uma situação vitoriosa segundo a qual, colocado sob os cuidados privados exercidos em nome do estado, é o logos mesmo que marcha uma boa marcha até a sua dissolução. Tal como a dissolução mesma do personagem Doutor que morre de forma simplória: o famoso médico finalmente ainda mais louco do que aqueles que pretendeu curar.

O que fazer o Doutor com os desejos, depois do rompimento da corda esticada que delimitava a altura da normalidade? Como escolher caminhos com a queda das placas que sinalizavam a direção correta dos corretos prazeres? Como saber se é conhecimento aquilo que se sabe sem a delimitação do que é não-saber? O saber do sujeito sobre ele mesmo é sempre resistência-fenômeno ao saber do poder sobre o sujeito. A destruição do quadro e a dissolução da média confundem todo sujeito assujeitado, despotencializado da produção criativa sobre si. O sujeito que acusa no outro excesso de redundância, sob o primado da menor distância, não encontra mais nada sem o ponto de chegada.

Envolvida em vantagens seculares, a Casa Verde rege-se, sobretudo, com o fim de suprimir a loucura. As exigências morais tornam-se táticas sempre que são assim solicitadas. Insere-se no seu texto fundacional o que doravante é problema da cidade. Problema da ciência. O espaço real da sociedade que a recebe de portas abertas, reservado o espaço da neutralidade, coloca toda a cidade em suspensão. Mas seu triunfo é preparado de antemão sobre o desatino desenfreado que segue não 
obstante as regras bem conhecidas. O gesto da segregação é ao mesmo tempo gesto de delimitação, conhecimento e reconhecimento do outro submetido a um determinado alcance designado pelo esquadro do estranhamento, circunscrito pelo espaço do internamento: uma casa "para agasalhar e tratar". Certamente não se trata apenas de um papel negativo de uma mera exclusão por diferença daqueles cujo comportamento destoa da "normalidade", mas, principalmente, de uma lógica inteira de organização social segundo a qual não apenas é possível formar um mundo a parte do desatino e da loucura, como também, perceptivelmente, organizar num papel o domínio da experiência social. "- A Casa Verde, disse Simão Bacamarte ao vigário, é agora uma espécie de mundo". E cada louco é um mundo nu mundo.

A Casa Verde é um local de confinamento, mas os saberes e os poderes que justificam sua existência não ficam confinados neste espaço de sequestro. Como a produção de si é toda produzida externamente, os saberes legitimadores da Casa Verde torcem as subjetividades. Vergam as existências na procura da média. A anormalidade não está fora da norma, a anormalidade é inclusa na norma como desvio, interrupção da média e, portanto, exerce coação direta quando sequestra o corpo, mas subsome indiretamente toda alma da cidade de Itaguaí, sobretudo a alma do Doutor. A média é sempre dependente de uma relação com o parâmetro (sempre móvel) e é essa mesma flexibilidade que torna tão fácil legitimar a violência dos poderes. Sendo a norma superior à lei, ela pode tanto produzir leis sem positivação como negar a aplicação de qualquer lei positivada. Tudo na Casa Verde é como nu mundo.

Em busca do insano denominador comum de uma realidade que se coaduna com o esquematismo de quem convence toda a sociedade de Itaguaí, o Alienista caminha por entre as articulações legais que regem o funcionamento social. Às margens, às expensas, das regras jurídicas, no entanto, vai sendo tramada uma precisa prática institucional; essa prática não meramente surpreende as regras jurídicas e sociais vigentes, como se realiza, perfectibiliza ao mesmo tempo negando-as e suspendendo-as - o que futuramente a polícia é, hoje, uma cabal expressão - essa prática precede as regras jurídicas de organização social de acordo com a consolidação da consciência social que não rompe exatamente com a unidade social. A sua 
pretensão de unidade social, a vigente, tampouco se dá a ver nitidamente em suas tramas latentes. Aos poucos uma organização teórica é constituída e uma alienada consciência social se expande, e permite lograr todos os corpos que para tal razão são solicitados. É possível dizer que existia e existe uma tendência para acreditar não na inocência de tais juízos, mas na sua verdade e na autônoma potência que têm para fascinar, dominar e organizar. Expandir e repetir-se. "Uma ideia nova e arrojada, própria para alargar as bases da psicologia". E, pois, toda uma população se acha incorporada, incluída por exclusão e reclusa na Casa Verde, local no qual funciona um conjunto de operações através dos quais a "loucura" irá, por assim dizer, reconhecer a si mesma.

Expandir e repetir-se. Expandir e repetir-se. Toda a resistência ao movimento de alienação ocorrido em Itaguaí é sustentado na arbitrariedade do Doutor que, ardilosamente, renuncia aos dividendos econômicos que acumulava. Sua astúcia desestrutura a resistência, pois a ambição científica é relacionada com a verdade, com a justiça e outros tantos termos que sempre articulam as violências institucionais com a consciência social. Discutir com a ciência é sempre mais profano que questionar o Doutor. A expansão dos poderes legitimados pelos saberes não é incompatível com a eliminação daqueles que detém o poder, tampouco dos discursos que estes enunciavam. O Alienista, por exemplo, é sabidamente uma das literaturas mais discutidas nas ciências médicas, assim como nas ciências jurídicas. Ocorre que os mecanismos de sequestro exercidos por tais saberes continuam em plena expansão e repetição. A própria ironia cáustica de Machado de Assis, como pôde ser deglutida pelo pensamento jurídico e médico de tal forma que ambos conseguem debater $O$ Alienista e, ao mesmo tempo, manter intacta a estrutura de pensamento (a mesma que sustentava a Casa Verde) nos Palácios da Justiça e nos manicômios, independente da forma com que sejam nomeados?

O livro é de Machado de Assis, mas a leitura também pode ser kafkiana. É certo que a organização metódica do Dr. Simão Bacamarte, sua arguta percepção científica e política, assim como sua posição social, não permitiriam a execução de um planejamento moral e científico que se escusasse à ordem jurídica reinante. E assim o que nessa mesma ordem pode haver de aparentemente arbitrário fica oculto nas suas 
relações articuladas em nome da sua própria profissão de fé - imbricada no todo do estado. É esse movimento que abriga, recolhe e encobre, por sua vez, toda uma articulação de poderes. Parafraseando Michel Foucault, gostaríamos de dizer que é por esses meandros que "a vida como objeto político foi de algum modo tomada ao pé da letra" ${ }^{3}$.

Se o coito interrompido foi a marca da vinculação entre o sexo e os dispositivos de sexualidade; se o homicídio em massa dos loucos pelo nazismo foi a marca da vinculação entre medicina e política; se a periculosidade é a marca da permanência de toda essa lógica estampada nas sentenças judiciais; se a violência escancarada das polícias é a marca de uma permanência; se um Tribunal de Justiça proíbe liminarmente uma manifestação; se não existem leis aplicáveis em defesa dos sequestrados em uma instituição prisional ilegal; então quais articulações de poderes sustentam nossas teorias sobre democracia na segunda década do século XXI?

A percepção científica do Doutor Simão Bacamarte não é obstáculo para os poderes de Itaguaí. Caso a ciência se mostre contrária à lei, é o que basta; a lei se suspende. O que importa é uma espécie de norma vigente sem significado, que é o efeito lógico de uma estrutura de toda forma coerente consigo própria. Toda sistemática corresponde a uma função, de forma que o excesso e radicalidade na tarefa de sistematizar não é o oposto da política, mas seu instrumento. Os poderes não constituem um bloco de material inatacável, mas uma esponja tentacular que expele e retém continuamente, em prol de sua manutenção. O poder político de Itaguaí está louco ou são de acordo com a proximidade da norma, da média, de forma que a resistência política e a resistência subjetiva são exatamente a mesma coisa e, portanto, devem receber o mesmo internamento. Por outro lado, a média não é exatamente um cálculo do padrão e seus desvios, a fórmula que produz o resultado permite variações que são continuamente inseridas e podem remodelar todo o quadro. Norma é sempre média, mas é também esquadro. Existe linguagem no cálculo e há política na linguagem: a linguagem/cálculo-política/linguagem.

\footnotetext{
${ }^{3}$ FOUCAULT, Michel. História da sexualidade, v. 1, p. 158. 
Ora, que obscura memória acompanha a loucura - e, ainda mais nesse caso, o Alienista? Em nenhum momento poderíamos dizer que o Dr. Bacamarte abusou das regras que se impõem àqueles que respeitam a boa ordem. Ele as usou; em consonância, elas também o usaram, seu tipo - "tipo ideal". Seria possível dizer que Dr. Bacamarte conseguiu uma consciência tranquila no que diz respeito, de um lado à justiça e à história, e de outro à medicina? Em Itaguaí, a todos moveu a confiança estável num progresso, traçado que fosse por obscuros percursos. Numa das crônicas que tivemos acesso, o cronista fala, por exemplo, de uma espécie de jogador, introvertido, animando secretamente essa memória. O que caracteriza esse ambiente é justamente a crença de estar se avançado mais rapidamente em direção à sua meta e ao mesmo tempo não lograr distingui-la com clareza suficiente. $E$, nesse mesmo movimento, absorver o louco numa massa literalmente indiferenciada - pois, quem são os loucos, afinal?

É justamente a obscuridade da classificação que propicia segurança ao Doutor; a ironia do dispositivo é ter como principal motor sua possibilidade lógica comprometida com a sua própria impossibilidade. Não fosse a ausência de convicção, a confusão dos conceitos, o terreno movediço no qual caminha... e o Doutor teria de abrir as portas da Casa Verde. A legitimação institucional possui alicerces tanto no absurdo da tarefa como na negação retórica do absurdo. Uma negação teórica. É preciso que seja aberrante, mas também é necessário sustentar a legitimidade. Sustentar-se e suspender-se. O que amedronta a população de Itaguaí é o que reforça o poder do Doutor: não sabemos quem são os loucos e temos uma ciência que legitima o seu assujeitamento classificatório, então todo aquele ainda não assujeitado deve legitimar a classificação, pois, não podendo provar sua sanidade, o ato de força aplicado ao insano é o que lhe dá razão. E não seria racional, neste contexto traiçoeiro, dispensar qualquer instrumento de auto-defesa. Ainda que tal instrumento defensivo implique espécie de festejo à cada sequestro estatal. Cada sujeito internado é a repetição de duas etiquetas: a etiqueta de insanidade ao outro, a etiqueta de sanidade para si.

O internamento, às voltas do qual se enxertaram as leis que regiam a prática jurisprudencial, permitiu sim uma ascendência médica não apenas sobre os insanos, 
mas sobre toda a cidade, marcando a sua história. Essa prática a que nos referimos alcançou em Itaguaí, na presença do Dr. Bacamarte, dos vereadores e de toda a população o patamar onde a lógica e a práxis se indeterminam e uma força-de-lei se exerce - como repetidas vezes o fez no curso histórico da linguagem ocidental hegemônica. O estado de exceção é a regra.

Irônico que a literatura denuncie que apenas a ficção poderia sustentar a ideia de que sanatórios existem para curar loucos ou que a prisão serve para ressocializar presos. Tais afirmativas dependeriam de uma terceira afirmação ainda mais alucinada: as leis teriam de existir para serem cumpridas. Simão Bacamarte restringe e estende a teia da loucura de acordo com os posicionamentos estratégicos dos atores e de sua própria legitimação como médico. Os habitantes de Itaguaí - exceto nos momentos de veneração não ponderados - igualmente ajustam-se e desajustam-se de acordo com a sombra da teia de insanidade que ameaça pousar sobre si. Toda afirmação de loucura no outro - assim como todo apontamento de sanidade - está envolto por uma discricionariedade arbitrária que só pôde ser sustentada através de um discurso falso o suficiente para que pareça ser coisa de cientista.

Consonante por via transversa, a ordem jurídica das coisas em Itaguaí apenas duplica a incriminação moral, assim como o faz também a explicação psicológica, em seu próprio sentido. O Doutor procura distinguir com maior rigor possível a alienação fingida da alienação autêntica. Então se efetiva o confisco do corpo, o seu caráter prático. A linguagem que mantém os loucos na Casa Verde - como dizem Kafka, Benjamin e Agamben ${ }^{4}$ - "vige sem significado", cerzida pela diferença entre o discurso científico-político (o teórico) e as práticas a contrário que se empreendem no estado sob as suas justificações (teóricas) - tudo muito bem organizado. A loucura, pois, como caso limite, evidencia as egrégias entranhas de uma determinada razão filosofante. " $A$ razão é o perfeito equilíbrio. Fora daí só insânia, insânia, e só insânia", disse o Dr. Bacamarte.

É incrível como as instituições mais violentas do Estado podem ter tanto poder com base em tão pouco saber. Ainda que legitimem o exercício de violência com base

\footnotetext{
${ }^{4}$ AGAMBEN, Giorgio. Homo sacer, p. 56. 
no saber, Itaguaí mostra como o poder é exercido sem ligações firmes com o saber que o legitima. Não há saber estruturado sobre a loucura que justifique o internamento em Itaguaí, o que pode ser aplicado aos internatos, as prisões e outros exercícios de violência que persistem até a contemporaneidade. É falso, portanto, o argumento de que tais violências decorrem de equívocos no saber legitimante. $O$ saber, de fato, nunca possuiu razão suficiente para o poder exercido. Os manicômios - assim como as prisões - não refletem a consequência de falhas na produção do saber, mas de aplicação arbitrária e intencionada de poderes que posteriormente se encontram com justificativas científicas.

Desse modo, o dentro e o fora da Casa Verde apenas transparecem. E claro que mil explicações podem ser dadas sem que nada se explique. Mas nada na narrativa parece correspondê-las para além da sua força autóctone. Por isso, o estado de exceção da existência vigorosa do logos que dá as caras para toda sociedade de Itaguaí é uma espécie de exigência (ela mesma excessiva) da qual se apropria o escritor Machado de Assis para exceder o estado de exceção. A força que daí advém sugere o encadeamento com a situação geral de ofuscamento, mantida através do reconhecimento dos sintomas que uma determinada percepção recolhe e estrutura ao seu bel prazer. Quando nesse conto de Machado de Assis triunfam as estruturas perceptivas lineares de uma razão filosofante que se basta a si mesma não há consequentemente um progresso do qual se possa efetivamente tirar proveito em nome de uma saúde pública, por exemplo, ou mesmo de uma prática ainda mais rudimentar de encontrar outros, simplesmente. A secreta coerência dessa lógica é rompida pelas fendas que Machado expõe narrativamente: a coincidência de sua própria irrealidade com a realidade do presente.

Simão Bacamarte - embora médico - era muito erudito nas táticas jurídicas de dominação social. Transparecia em cada libertação concedida um certo ar de emancipação inconcebível com o ato de soltura. A prática da liberdade é um exercício que precisa estar sempre em movimento. O exercício da liberdade precisa de espaço para sua prática, o exercício do Direito precisa de restrição espacial. O confinamento legitima a si próprio quando denomina liberdade a suspensão do sequestro. A interrupção do sequestro institucional surge como elemento democrático ou falso 
discurso ético: se houve o livramento, então há justiça. Nesta lógica, a justiça é o ato de prender e soltar, prender e soltar: Expandir e repetir-se.

Como um relâmpago, aqui também o tempo presente é aquilo que brilha ao mesmo tempo em que se desvanece. O que interrompe o domínio da patologia e escande a potência vazia da lei que vigora em Itaguaí leva sua articulação total ao extremo da desarticulação. O seu próprio esquema de coerência esgota-se na ausência do ar que foi o seu outro. Conforme afirma Maurice Blanchot, ali "a obra literária está em suspensão, entre sua presença visível e sua presença legível" ${ }^{5}$. 0 passado no qual se narra a história da Casa Verde é presente para nós porque o herdamos do movimento incessante de repetição que vem se retroalimentando em cada instante que se autocontempla na sua própria imagem de alienação. O alienista aliena.

Assim, quando a democracia precisa acontecer, é desativada. A reativação, porém, reinaugura um estado de coisas que seria democrático e que, portanto, teria sido apenas suspenso. Cada suspensão equivale a reafirmação do estado de exceção, mas é lido como um novo fortalecimento das instituições democráticas. De forma que interpretamos como desvios democráticos o extermínio de 111 presos, o desligamento de emissoras de rádio que noticiam violência policial, a destruição de equipamentos de gravação em manifestações populares e a manutenção de instituições jurídicas que torturam, estupram e matam. Não se trata de negar a existência deste ou daquele momento democrático, mas sustentar que a liberdade deste ou daquele louco na Casa Verde não corresponde à uma negação progressiva da exceção, mas a um ardiloso processo de manutenção institucional.

O homo medicus dessa narrativa, o Dr. Bacamarte, (a quem nada obsta, hoje, chamarmos de o grande homem médio) ocupa o lugar central na organização da loucura em seus domínios, ancorado em toda a sua tradição e arraigado em todo o classicismo que venha lograr compreender as exigências das suas questões de fato. Mas não é o lugar de um árbitro, o justo meio, que ele necessariamente ocupa, no entanto. Ainda que se estabeleça na suspensão da linguagem que opera, isto é, ainda que estabeleça na vigência sem significado da sua linguagem a divisão entre loucura e

\footnotetext{
${ }^{5}$ BLANCHOT, Maurice. O livro por vir, p. 354. 
sanidade, entre saúde e doença, o Doutor arroga-se também como bastião da sociedade; e é como um guardião diante das portas da razão, a fim de proteger ela própria e todos os demais que a ela devem as suas propriedades e as prosperidades das suas existências, que ele se posiciona e sorri um "sorriso tanto ou quanto filosófico". Como o guardião kafkiano da lei, Simão Bacamarte sabe que a sua porta está reservada aparentemente para a segurança de todos aqueles que aspiram ser por ela abrigados e por baixo dela atravessarem sua passagem. Mas essa porta está reservada principalmente para aquele que é único e a quem ela finalmente se destina. Assim, segundo as suas próprias palavras, ele não precisaria dar as razões dos seus atos, mandos e desmandos para os que se revoltaram com o caráter déspota das suas ações como Alienista - "não dou razão dos meus atos de alienista a ninguém, salvo aos mestres e a Deus".

É claro que havia ciência no Doutor. É claro que havia positividade na Casa verde. A biopolítica possui como característica fundante a produção, mais do que a negação. É necessário suscitar progresso, demonstrar a semelhança do molde com a fabricação. O assujeitamento não é mais a espada do soberano caindo sobre a cabeça do súdito, mas todo um processo exaustivo de produção de saberes, rearticulação de palavras e escolhas pedagógicas. É preciso educar para o assujeitamento, delinear todo um quadro de compreensão onde a liberdade esporádica possa ser vista como democracia em expansão. Visualizar a soltura como vitória democrática e não como manutenção da exceção é, também, uma questão de educação.

As curas verdadeiras das falsas doenças ou as curas falsas das verdadeiras patologias compartilham toda a encenação da justiça e da organização do estado das coisas em Itaguaí. A natureza científica e médica que atesta o internamento dos doidos e a queda na objetividade a que sucumbiram, respeita um movimento que vale ao mesmo tempo como descrição e compressão, segundo arcaicas estruturas dadas de antemão. Por trás da crônica da legislação, tudo o que diz respeito à região obscura da nossa consciência transforma-se naquilo que é mesmo obscuramente o modo mais secreto de dilaceramento da experiência. E isso garante à sociedade, de forma quase indescritível, a forma da sua consciência. A indigência do mundo não pode esquivar-se à indigência do estado. E como coisa de estado é que a Casa Verde estava reservada 
desde a sua fundação para um único louco. O que, por assim dizer, "Simão Bacamarte não contrariou".

Absolutamente obcecado com o laboratório de nu mundo que pretendia construir, Simão Bacamarte não compreendeu a verdadeira genialidade de seu projeto: O Doutor não foi apenas diretor de um pequeno mundo denominado Casa Verde, mas foi sujeito assujeitado de um processo espelhado ao que almejava arquitetar. Distanciando cada indivíduo de Itaguaí do exercício de suas próprias existências, na promessa de ciência total o suficiente para entregar a prática ética pronta para cada habitante, como um manual perfeito de interação social, Simão Bacamarte ainda era protagonista de cena social montada por espécie de jogador introvertido, animando secretamente o enredo e sorrindo de forma enigmática para o destino do Doutor. Como todo soldado da Razão, o Doutor abdicou de saber que era explorado por um Jogador que nunca precisou existir.

Assim, o sofrimento do outro logrado como razão de ser da Casa Verde alcança o último grau da sua exequibilidade na evidência do vazio de conteúdo que vigora sob sua égide. "Desenganado da legalidade", o controle biopolítico aí está assentado sob o medo que grassa nos subterrâneos da consciência geral em Itaguaí; esse controle para o qual "era difícil imaginar mais racional sistema terapêutico" a lidar com a loucura, com a sociedade como um todo e com o futuro, metamorfoseia-se, então, de forma cabal nas ruínas da Casa Verde. Os seus restos, uma espécie de resíduo sólido e altamente erguido - os cronistas assinalam como primeiro e último testemunho da vitalidade cadavérica do Doutor que a ela se juntou em nome da saúde e da ciência e que a ela se entregou em nome do sofrimento em si. 


\section{REFERÊNCIAS BIBLIOGRÁFICAS}

AGAMBEN, Giorgio. Homo sacer: o poder soberana o e avida nua, 1. Trad. Henrique Burigo, Belo Horizonte: Editora UFMG, 2010.

BLANCHOT, Maurice. O livro por vir. Trad. Leila Perrone-Moisés. São Paulo: Martins Fontes, 2005.

FOUCAULT, Michel. História da sexualidade, 1: a vontade de saber. Trad. Maria Thereza Albuquerque e J. A. Albuquerque. São Paulo: Graal, 2006. 